\title{
Foto-ostentação: um novo paradigma fotográfico? ${ }^{1}$
}

\section{Photo-ostentation: a new photographic paradigm?}

Michel de Oliveira ${ }^{2}$

1 Uma versão preliminar deste artigo foi apresentada no Grupo de Trabalho Fotografia do XXXVIII Congresso Brasileiro de Ciências da Comunicação. 


\section{Resumo}

Este exercício conceitual objetiva compreender os usos da fotografia nas dinâmicas da interação em rede. Para isso, traça um histórico da ostentação e apresenta considerações sobre o papel da imagem fotográfica na sociedade do hiperespetáculo. A hipótese levantada é a de que as reconfigurações da fotografia não se encaixam nos paradigmas preestabelecidos, o que torna necessário uma conceituação crítica para descrever o regime que se consolida, voltado à exposição do cotidiano em detrimento do valor de culto atribuído aos registros domésticos.

Palavras-chave

Foto-ostentação, fotografia, cultura visual, midiatização do cotidiano.

\section{Abstract}

The objective of this conceptual exercise is to understand the uses of photography in the dynamics of network interactions. Thus, we present a history of ostentation and considerations about the role of photographic images in the hyper-spectacle society. The hypothesis is that the reconfigurations in photography do not fit the pre-established paradigms, which requires a critical conceptualization to describe the consolidating regime, focused on daily exposure, instead of the worship value attributed to domestic records.

\section{Keywords}

Photo-ostentation, photography, visual culture, mediatization of everyday life. 


\section{A abertura das cortinas}

Em fevereiro de 1968, o artista plástico Andy Warhol publicou no catálogo de sua exposição no Museu de Arte Moderna de Estocolmo, Suécia, a irônica profecia: no futuro, todos serão mundialmente famosos por 15 minutos (GUINN; PERRY, 2005). O prenúncio do ícone da pop art ganhou repercussão e se tornou um dos motes da indústria cultural norte-americana.

Um ano antes, o crítico e polemista francês Guy Debord lançou A sociedade do espetáculo, que reunia aforismos críticos à crescente midiatização e ao acirramento do consumo e do capitalismo. O espírito do tempo no final daquela década conduziu pensadores e artistas a compreender as bases da nova ordem social que se consolidava: consumista, midiatizada e visual.

Warhol e Debord vislumbraram o abrir das cortinas. Gradativamente, o espetáculo tomou todas as dimensões da vida. A busca pelos 15 minutos de fama passou a fazer parte do ideário dos indivíduos na sociedade de consumo. "O que aparece é bom, o que é bom aparece", pontua Debord (2002, p. 17). Nesse jogo de ver e ser visto, houve profunda transformação nas rotinas cotidianas. As imagens técnicas colonizaram as instâncias: do nascimento à morte, da intimidade à vida pública, do trabalho à diversão.

Pouco mais de duas décadas após a popularização da internet, não foram só os aparatos técnicos que mudaram. As transformações tecnológicas acarretaram alterações sociais profundas e, recursivamente, as mudanças no contexto das relações humanas demandaram modificações tecnológicas. Notebooks, tablets e smartphones instituíram outras formas de interação social; voyeur e exibicionista passaram a se encontrar no mesmo ambiente virtual da internet.

A sociedade em rede exacerbou características sociais já existentes: a visibilidade tornou-se hipervisibilidade, o consumo expandiu-se como hiperconsumo e a conectividade se alargou como hiperconectividade. A sociedade, que era espetacular, tornou-se hiperespetacular: "o hiperespetáculo é a nova ordem mundial", defende Juremir Machado (2013, p. 66). 
Esse processo de transição da sociedade do espetáculo para a do hiperespetáculo tem como uma de suas consequências a mudança no regime da visualidade. As reconfigurações pressupõem outras formas de representação e dos usos sociais das imagens técnicas. Conforme destaca Kossoy (2012, p. 144, grifo do autor): "é na decifração das finalidades a que se destinavam [e se destinam] as imagens que se encontrará um rico veio para a compreensão da estética da fotografia nos diferentes períodos de sua história".

Dessa tentativa de decifração, decorre o questionamento que norteará esta discussão: os registros fotográficos produzidos no âmbito da sociedade hiperespetacular se encaixam nos paradigmas existentes? Para esboçar respostas possíveis a essa questão, parte-se do pressuposto de que a produção fotográfica destinada às redes de interação na internet subverte a lógica clássica de preservação da memória pessoal e familiar, transformando os registros domésticos e cotidianos em artefatos de exibição, forjados nos parâmetros hiperespetaculares.

\section{A gênese social da ostentação}

Para compreender o que será conceituado como foto-ostentação, faz-se necessário considerar a conjuntura que alicerçou as práticas honoríficas e de distinção no contexto social. Ainda que não sejam desprezados os fatores antropológicos que envolvem as práticas distintivas, a abordagem adotada tem como foco principal a discussão socioeconômica.

Lipovetsky (1989, p. 32) aponta o surgimento do sistema de moda, em meados do século XIV, como marco na consolidação dos mecanismos sociais de ostentação: "com a moda começa o poder social dos signos ínfimos, o espantoso dispositivo de distinção social conferido ao porte das novidades sutis". A distinção pelo vestuário nasceu no âmbito da aristocracia, adornada pelos trajes marcados pelo exagero de veludos e brocados. Mas foi o crescimento do poderio econômico da burguesia e a formação do Estado democrático que impulsionaram a variação do vestir-se, dando abertura para a expressão das individualidades - restrita aos privilegiados que tinham direito à visibilidade. 
O desenvolvimento do sistema de moda, marcado pela renovação cíclica dos gostos, foi simultâneo à emergência do individualismo enquanto filosofia dominante nas sociedades ocidentais. "Com a moda, vê-se muito cedo o advento de um individualismo mundano em todos os sentidos do termo, à espreita das marcas da unicidade da pessoa assim como da superioridade social" (LIPOVETSKY, 1989, p. 48).

Foi nesse contexto, caracterizado por transformações estéticas, econômicas e filosóficas, que se estabeleceu o jogo da visibilidade como componente social. "A moda tem ligação com o prazer de ver, mas também com o prazer de ser visto, de exibir-se ao olhar do outro" (LIPOVETSKY, 1989, p. 39). O sistema de moda se consolidou como jogo teatral, marcado pelas práticas distintivas e pela conveniência.

Ao analisar as normas de distinção na sociedade industrial do final do século XIX, o economista Thorstein Veblen (1983) aponta dois pilares que são fundamentais para a sustentação dos princípios ostentatórios: a emulação pecuniária - ou seja, a distinção pela propriedade privada e pela posse de bens - e o ócio conspícuo - isto é, utilizar o máximo de tempo livre no desenvolvimento de atividades que não sejam produtivas, apenas agreguem valor honorífico, como cultivar rígidas regras de etiqueta ou dedicar-se à caça esportiva. Características encontradas no que o pensador denomina classe ociosa, afeita às realizações dignitárias, que mobilizam ações distintivas - como o esporte, a arte, o jogo - em contraposição às tarefas indignas, ordinárias e cotidianas, a exemplo do trabalho e dos afazeres domésticos.

Além de honoríficas, as regras ostentatórias têm a função de estabelecer parâmetros de manutenção no sistema social. São normas que precisam ser observadas e mantidas mesmo por aqueles que não fazem parte das classes dominantes. Como descreve Veblen (1983), a classe ociosa está no topo da estrutura social, ditando valores e costumes, que devem ser observados por todas as classes inferiores da escala.

Cada sociedade, em determinado espaço e período, cultiva normas de distinção específicas. Apesar disso, "a mudança de padrões e pontos de vista é 
gradual; ela raramente resulta na subversão ou total supressão de um ponto de vista aceito no passado" (VEBLEN, 1983, p. 8). Dessa maneira, ainda é possível identificar o poder de propriedade e o ócio como características distintivas presentes na sociedade contemporânea. No entanto, resguardadas as devidas transformações históricas e sociais, na sociedade hipermoderna o poder de posse se alarga para os mais diversos bens de consumo e de capital simbólico.

O ócio, por sua vez, pode ser identificado nas mais diversas formas de aproveitamento do tempo, seja com a supervalorização da indústria do turismo ou da espetacularização de situações corriqueiras, como o ato de comer ou de ir à academia. Nesse contexto, os registros fotográficos do cotidiano reforçam o constante apelo ao ócio. Afinal, é preciso dispor de tempo - por mínimo que seja - para posar, editar e gerenciar a publicação nas redes sociais da internet.

\section{Usos ostentatórios da fotografia}

A fotografia, desde sua gênese, esteve ligada às demandas de distinção. O primeiro suporte de reprodução fotográfica, o daguerreótipo, foi inserido na lógica comercial de artigos de luxo. Na pequena placa de metal banhada a prata, fixavase a imagem única, guardada como joia em estojos cuidadosamente adornados. "A foto tornava-se, então, não só símbolo de modernidade como marca de status e de civilização; uma distinção nas mãos de poucos" (SCHWARCZ, 1998, p. 523).

Ao analisar o contexto social do início da história da fotografia, Annateresa Fabris (2004, p. 29) destaca que "os altos preços do daguerreótipo e das produções de fotógrafos como Nadar, Carjat, Le Gray colocaram o retrato num âmbito social restrito, permitindo-Ihe atestar apenas a ascensão da alta burguesia". Essa circulação limitada pelo poder aquisitivo fez o daguerreótipo se tornar objeto de cobiça, sedimentando a fotografia, no imaginário coletivo, como algo de valor, a ser estimado e apresentado como insígnia distintiva.

Mas a técnica fotográfica, alçada ao domínio público após seu anúncio oficial, em 19 de agosto de 1839, na França, logo se tornou mercadológica, e passou por gradativas transformações, o que barateou consideravelmente o processo. 
As chapas de metal polido deram lugar a placas de vidro ou lâminas de ferro, técnicas conhecidas como ambrotipia e ferrotipia, respectivamente.

Com o desenvolvimento do processo de negativo e positivo, idealizado por Fox Talbot e patenteado em 1841, as imagens fotográficas puderam ser reproduzidas em papel. A técnica foi aperfeiçoada e serviu como base para o invento registrado em 1884 por Eugène Disdéri, a carte de visite, que consistia em um pequeno retrato, reproduzido em papel albuminado, colado sobre cartão de papel rígido, geralmente assinado com a marca do estúdio fotográfico.

O processo inventado por Disdéri possibilitou o registro de diversas imagens em uma mesma chapa, o que barateou o custo de produção das fotografias. As cartes de visite tornaram-se populares no início da década de 1860, o que impulsionou sua circulação social como objeto de troca entre familiares e nas rodas sociais. Os retratos eram preservados em álbuns, instituindo a prática de colecionar fotografias.

Os registros fotográficos tornam-se artefatos de sociabilidade e instauradores da nova cultura visual que conquistou o espaço doméstico. Nesse contexto, não se pode desprezar a prática de presentear cartões-postais, demonstração de lembrança que carregava consigo a ostentação dos lugares visitados, das paisagens estrangeiras encaminhadas a amigos e parentes.

No início do século XX, a fotografia já estava inserida nos mais diversos âmbitos, da imprensa ao registro dos ritos e cerimônias familiares. A circulação social de fotografias consolidou a cultura visual expoente, que fazia conhecer o mundo através dos álbuns, dos postais, dos magazines e revistas ilustradas e, posteriormente, das películas do cinema. As imagens técnicas povoaram as mais distintas civilizações, transformando costumes e cenários.

Com a invenção de câmeras portáteis automáticas, que se propagaram rapidamente no alvorecer do século XX, o cidadão das camadas menos abastadas passou a produzir as próprias imagens. Essa mudança na produção fotográfica possibilitou o registro de cenas do cotidiano familiar, retratos da intimidade que resguardariam momentos de afeição coletiva ou as divertidas cenas de férias. 
Fotografar tornou-se ótimo hobby para os herdeiros da burguesia, que encontraram no manejo da câmera um excelente ócio conspícuo.

A acolhida da fotografia pelas classes burguesas foi fundamental na difusão e aperfeiçoamento da técnica. As cíclicas mudanças de equipamento ou a invenção de novos aparatos servia para alimentar o gosto burguês pela novidade. No entanto, apesar dessas transformações técnicas, a linguagem e os usos sociais da fotografia se mantiveram praticamente inalterados por mais de um século, fato que se sustentou no gosto burguês de cultivo às tradições.

$\mathrm{Na}$ era do hiperespetáculo é possível observar que esse ambíguo sistema de inovação técnica e manutenção de estilos passa por significativa revisão. Com a sociedade em rede, hiperconectada, é possível identificar novos usos sociais da fotografia, que ainda mantêm conexão com a tradição burguesa de ostentação e visibilidade, mas que, por outro lado, se afasta radicalmente da manutenção solene da intimidade resguardada pelo álbum de família.

\section{Fotografia doméstica: do culto à exposição}

Fotografar é "sobretudo um rito social", afirma Susan Sontag (2004, p. 18). A fotografia, como todas as produções humanas, se sustenta socialmente ao encontrar significações expressas como função em alguma instância da vida dos indivíduos. No entanto, identificar essas funções não é tão simples, visto que são interiorizadas culturalmente como acontecimentos naturais.

Em estudo encomendado pela Kodak na década de 1960, o sociólogo francês Pierre Bourdieu (2003) observou os usos sociais da fotografia doméstica. Ao analisar os acervos pessoais de campesinos, o pesquisador identificou cinco funções principais para a fotografia no microcosmo familiar: a) proteção da memória contra a passagem do tempo; b) artefato de interação comunicacional e de troca afetiva com os demais membros da família; c) realização pessoal; d) prestígio social; e e) distração.

Antes, os registros da intimidade familiar circulavam no contexto privado. O álbum era artefato de devoção, relicário de lembranças a serem compartilhadas 
com parentes ou amigos mais chegados. Utilizar registros íntimos como elemento de exibição, mesmo no ambiente doméstico, era algo reprovado nas comunidades tradicionais, pois, segundo Bourdieu (2003), as fotografias dos ritos familiares eram demasiado solenes e íntimas para serem expostas indiscriminadamente.

Com as transformações acarretadas pela internet, o que antes era condenável se tornou aceitável e corriqueiro: expor os retratos familiares nas redes sociais da internet. Isso subverteu a lógica que regia a fotografia doméstica, apresentada por Bourdieu (2003), de não fotografar o que se tinha diante dos olhos todos os dias. Se antes a maior parte das fotografias de família se voltava ao registro de cerimônias e ritos de passagem, hoje se fotografa o almoço ou o banho do cachorro.

A gradativa mudança na função da fotografia doméstica acarreta na transposição do valor de culto para o valor de exposição, conceitos defendidos por Walter Benjamin (2012) no ensaio "A obra de arte na era de sua reprodutibilidade técnica". O valor de culto se refere ao uso ritual de determinado artefato, que deve ser resguardado e preservado, podendo ser exibido apenas em determinadas ocasiões solenes. Com a possibilidade de reprodução técnica, fortemente impulsionada pela invenção da fotografia, "o valor de culto começa a recuar em todas as frentes diante do valor de exposição" (BENJAMIN, 2012, p. 188).

As imagens técnicas foram inseridas no sistema de circulação massiva; a contemplação, substituída pela visão espetacular do consumo; os registros passaram a ser acometidos pela obsolescência programada, tornando-se perecíveis. Apesar dessa mudança incitada pela fotografia, Benjamin (2012, p. 189) vislumbrou a sobrevivência do valor de culto nos retratos: "o refúgio derradeiro do valor de culto foi o culto à rememoração, consagrada aos amores ausentes ou defuntos. Nas antigas fotos, a aura acena pela última vez na expressão fugaz de um rosto humano".

A exacerbação da cultura da visibilidade, todavia, parece exorcizar da fotografia doméstica o seu valor de culto. Os registros, que antes deviam ser preservados dos olhos exteriores, são submetidos à exposição pública; em vez da perenidade do documento, a sobrevida efêmera do arquivo. A fotografia, acusada de profanar as imagens ao destituí-las de seu valor ritualístico, se torna 
alvo da própria mirada mortífera, tal qual a Medusa ao se ver refletida no escudo espelhado de Perseu.

\section{Demandas da hipervisibilidade}

O início do século XXI foi marcado pela fragmentação da intimidade como valor social. Se nos séculos anteriores foram criados sistemas para separar o público do privado, em pouco menos de duas décadas essas estruturas ruíram ante as telas dos dispositivos conectados à internet: "chegamos a uma sociedade pan-óptica em que a paranoia da vigilância nos torna vítimas de câmeras que não cessam de nos enforcar, abolindo a esfera da privacidade" (FONTCUBERTA, 2012, p. 73).

É preciso sorrir todo o tempo, pois não há hora nem lugar para ser filmado ou fotografado - e não mais por causa das câmeras de vigilância. Os aparelhos e gadgets de captura, edição e divulgação de fotografias e vídeos estão por toda parte. O ato fotográfico tornou-se ordinário e completamente ubíquo: "Há alguns anos fazer uma foto era um ato solene reservado a ocasiões privilegiadas; hoje disparar a câmera é um gesto tão banal quanto coçar a orelha", observa Fontcuberta (2012, p. 30).

Os usuários de aparelhos conectados à internet são superexpostos diariamente a uma quantidade vertiginosa de imagens: publicidade, memes, selfies, registros jornalísticos, vídeos, gifs. Não se pode desprezar que essas reconfigurações da visibilidade são forjadas e atendem a demandas mercadológicas, que acabam sendo incorporadas às práticas cotidianas. A fotografia, que já havia sustentado grandes impérios industriais, a exemplo da Kodak, se tornou ainda mais lucrativa.

Se na era da televisão os indivíduos eram acusados de recepção passiva dos conteúdos, em tempos de internet é outro o estatuto vigente: o imperativo da produção. É preciso tornar público o que se sente, o que se veste, o que se faz, o que se come - alimentar as redes, ironicamente falando. Esse sistema de atualização constante faz parte da estrutura econômica que sustenta os 
milionários donos das empresas digitais. "A ilusão da gratuidade total é a quimera dos internautas", ironiza Machado (2013, p. 71). Neste período, em que trabalhar passa a ser encarado como algo ultrapassado, muitos são os que produzem conteúdo gratuitamente para as redes virtuais.

Além de trazer outras configurações para o sistema econômico, a hipervisibilidade estabelece padrões de comportamento. Na avalição de Sibilia (2008, p. 77), a tendência exibicionista ultrapassou os limites da internet e passou a configurar a vida cotidiana espetacularmente, fato que não deve ser tratado simplesmente como invasão de privacidade, mas como "fenômeno completamente novo". De acordo com Machado (2013, p. 27), a novidade desse fenômeno é a extinção de limites: "sociedade e espetáculo são a mesma coisa. O espectador é protagonista".

Os indivíduos passaram a ser personagens da própria existência. Tornam-se "indivíduos-espetáculo" (LIPOVETSKY; SERROY, 2011, p. 86). Essa midiatização do cotidiano formata a vida para o jogo de visibilidade, no qual "tendências exibicionistas e performáticas alimentam a procura de um efeito: o reconhecimento nos olhos alheios e, sobretudo, o cobiçado troféu de ser visto. Cada vez mais, é preciso aparecer para ser" (SIBILIA, 2008, p. 112, grifos da autora).

Ao se instituir a visibilidade como um dos valores centrais das relações sociais, há o distanciamento dos indivíduos e o consequente enfraquecimento dos vínculos humanos. De acordo com Machado (2013, p. 131), a sociedade do hiperespetáculo se resume a "um conjunto de imagens mediando pessoas sem necessidade imperativa de relação concreta, exceto comercial ou de atualização de dados".

Em vez de laços sociais mais fortes, há relações protocolares que têm efeito sobre a subjetividade. Para Lipovetsky e Serroy (2011, p. 85), "a era da celebridade para todos anunciada por Warhol chegou. Com seu quinhão de vazio: ser conhecido por nada, a não ser por ser conhecido". Vazio que reverbera ecos de insegurança coletiva e de solidão. 


\section{Em defesa de um novo paradigma fotográfico}

Do daguerreótipo às selfies, muitas foram as mudanças tecnológicas e sociais. Após seu anúncio público, a fotografia esteve presente no cotidiano, a exercer as mais diversas funções: dos registros documentais aos álbuns de família, dos arquivos policiais às galerias de arte, das revistas ilustradas às lápides. A própria existência se atesta fotograficamente por meio dos documentos oficiais; o indivíduo não existe legalmente se não for fotografado.

Ao longo desse período de interação simbiótica entre sociedade e fotografia, é possível destacar três grandes regimes fotográficos: a foto-documento, a foto-expressão e a foto-recordação. Paradigmas ${ }^{3}$ que, ao longo da história, entrecruzaram-se e afastaram-se, mantendo interações cujos limites ora se apresentavam muito delimitados, ora se demonstravam difusos.

Neste ponto, é possível retomar a questão central desta discussão: afinal, as fotografias que são agora produzidas se encaixam nos paradigmas existentes? Pode uma selfie ser considerada registro documental? Ou a fotografia do prato de comida ser recebida como forma de expressão? Ou o registro da ida à academia como foto-recordação? Sim e não.

Sim, uma selfie pode ser defendida como registro documental do cotidiano, por mais ordinária que aparente ser. A fotografia do prato de comida não deixa de ter seu valor expressivo, pois, como toda produção humana, a ela está atribuída valor estético. E por mais que a ida à academia constitua um momento banal, seu registro não deixará de suscitar recordações, caso essa fotografia seja recuperada algum dia.

Mas essa defesa se baseia em questões ontológicas, ou seja, inerentes a toda e qualquer fotografia. O que deve ser observado, no entanto, são os usos e a intencionalidade por trás de cada imagem - ou de um conjunto delas -, que deve ser avaliada em seu contexto social e histórico. Retomando o que afirma Kossoy (2012, p. 144), é na identificação da finalidade que se encontra a decifração estética da fotografia em determinado período. 
A partir dessa compreensão, é possível acusar publicamente as fotografias vernaculares contemporâneas: uma selfie não é feita com intencionalidade documental; o clique do prato de comida não almeja expressividade; o retrato em frente ao espelho não visa conservar o instante como registro mnemônico. A hipótese aqui levantada é a de que as fotografias produzidas em tempos de hiperconexão não se enquadram nos paradigmas existentes. Parte-se do pressuposto de que constituem uma categoria nova, registros da sociedade hiperespetacular: foto-ostentações.

Essa defesa do novo paradigma se baseia na principal questão que norteia a história e os usos sociais da fotografia: a memória. O papel mnemônico está tão imbricado à imagem fotográfica que Kossoy (2009, p. 132) é categórico ao afirmar que "fotografia é memória e com ela se confunde". Ao analisar a finalidade dos registros produzidos para as redes sociais na internet, é possível perceber a reconfiguração do atributo memorial à qual a fotografia esteve atrelada ao longo de mais de um século e meio.

Essa ruptura é observada por Fontcuberta (2012, p. 29), que afirma: "a fotografia esteve tautologicamente ligada à memória, e na atualidade esse vínculo começa a ser rompido". O autor chega a essa conclusão ao observar a rápida obsolescência das fotografias:

Definitivamente as fotos já não servem tanto para armazenar lembranças, nem são feitas para ser guardadas. Servem como exclamações de vitalidade, como extensões de certas vivências, que se transmitem, compartilham e desaparecem mental e/ou fisicamente (FONTCUBERTA, 2012, p. 32).

No lugar da preservação da memória, o que ganha destaque são as outras funções apontadas por Bourdieu (2003): a realização pessoal, o prestígio social e a distração. Com essa mudança de finalidade, Fontcuberta (2012, p. 30) defende que é necessário repensar a própria história da fotografia: "caberia rever a evolução da fotografia e inscrevê-la também, tanto em uma história da curiosidade quanto em uma história do espetáculo". 
Os regimes memoriais atribuídos à fotografia - documental, expressivo e afetivo - parecem perder espaço para a memória imagética, ou seja, as imagens não se dirigem mais à preservação, à expressão ou às emoções, mas ao universo das próprias imagens (ver Tabela 1), em um sistema de autorreferência.

Tabela 1: Regimes fotográficos e sua relação com a memória4.

\begin{tabular}{c|c|c}
\hline Paradigma fotográfico & Exemplos & Regime mnemônico \\
\hline Foto-documento & $\begin{array}{c}\text { Fotografia histórica, fotojornalismo, } \\
\text { ensaio etnográfico }\end{array}$ & Memória histórica \\
\hline Foto-expressão & $\begin{array}{c}\text { Fotografia artística, fotografia de moda, } \\
\text { fotografia publicitária }\end{array}$ & Memória estética \\
\hline Foto-recordação & Fotografia do álbum de família & Memória afetiva \\
\hline Foto-ostentação & $\begin{array}{c}\text { Fotografia para publicação nas redes } \\
\text { virtuais de relacionamento }\end{array}$ & Memória imagética \\
\hline
\end{tabular}

A ruptura com os parâmetros mnemônicos, culturalmente conferidos à fotografia, faz com que o paradigma da foto-ostentação institua o medo da perda da memória. Como consequência, a produção de imagens fotográficas entra em descontrole, o que caracteriza o excesso da sociedade de consumo. Quanto mais medo, mais imagens: "imagens são, por natureza, fóbicas. Evocam e atualizam o medo primordial da morte, uma vez que elas originalmente foram feitas para vencer a morte", destaca Baitello Junior (2005, p. 17).

Nesse contexto, a disfunção da lógica documental leva à hiperdocumentação de instantes fúteis. Coleções de pratos de comida, fotos de viagens, selfies, os livros lidos, os looks do dia. A foto-ostentação transforma tudo em cena, é da ordem do descartável e do perecível. Em vez de foto-recordações, foto-arquivos arquivos mortos que, possivelmente, nunca serão recuperados. 


\section{Foto-ostentação: funções e implicações}

A principal implicação instituída pela foto-ostentação foi a transposição da fotografia doméstica do âmbito privado e afetivo para o sistema midiático (OLIVEIRA; BONI, 2015). O imperativo é a atualização constante e a rápida substituição dos conteúdos. Os registros pessoais são inseridos no contexto do hiperconsumo, e não mais servem de relicário afetivo, mas como produto, regido pela obsolescência e imediatismo.

Os apelos à visibilidade e à exibição reconfiguraram a organização social, atribuindo novos valores e funções às imagens técnicas. Fontcuberta (2012) observa que compartilhar fotografias funciona como um novo sistema de comunicação social, ritual de comportamento que está sujeito às normas de etiqueta e cortesia. É preciso ponderar, no entanto, que as atuais reconfigurações permitem compreender as relações que sempre foram estabelecidas pela fotografia - mídia que nunca foi considerada independente, mas figuração secundária - de se apresentar como vetor comunicativo, sujeito às regras sociais, estabelecendo formas de interação baseadas na substituição do corpo e na distância.

No contexto da interação virtual, são três as funções principais da fotoostentação: a) a sociabilidade, com trocas simbólicas mediadas pelas imagens técnicas; b) a ostentação dos signos distintivos e do consumo; e c) a performatização da intimidade e a midiatização do cotidiano.

Enquanto elemento de sociabilidade, a foto-ostentação transmuta a matéria corpórea em imagem digital, para que o indivíduo possa interagir no ambiente virtual. No lugar do avatar figurativo, a própria representação fotográfica, o corpo simuladamente transformado em bits computacionais.

As performatividades digitais mediadas pelas imagens técnicas mimetizam as regras de conduta e as normas sociais vigentes no mundo material. Isso faz com que a foto-ostentação seja interpretação do que seu produtor considera como signos honoríficos, seja por meio do consumo material - como um prato de comida, o sapato novo, a viagem a um ponto turístico -, seja pela valoração 
imaterial - a exemplo das saídas com os amigos, a leitura de um romance clássico, o corpo sarado no espelho da academia.

No regime da foto-ostentação não há tema para a fotografia, pois tudo pode ser fotografado. No entanto, os registros não são gratuitos; pelo contrário, seguem a lógica de visibilidade baseada no poder de alcance da imagem. O registro de instantes fúteis coloca a fotografia no âmbito do entretenimento.

Tudo que o indivíduo considera que irá Ihe atribuir valor é transformado em figuração e compartilhado. A fotografia não existe por causa do momento, mas o momento é que existe por causa da fotografia - é a inversão radical de uma lógica que envolve experiência, afetividade e memória. Elementos que, somado a outros, servem como artefatos de coesão para a construção da identidade e da narrativa de vida dos indivíduos.

\section{Algumas considerações}

A foto-ostentação é imagem midiática, gestada na sociedade de consumo, que impulsiona a consequente produção de mais imagens. Sua existência se deu com a reconfiguração das formas de representação e da função social das imagens técnicas desencadeada pelas transformações sociais e tecnológicas.

Enquanto a foto-documento se propõe substantiva, ou seja, atestado de que algo aconteceu ou alguém existiu, a foto-ostentação é adjetiva, busca agregar valor ao sujeito. Apesar disso, a foto-ostentação dissimula seu lado ficcional, apropriando-se da herança positivista da fotografia documental para se apresentar como registros confiáveis. A foto-ostentação reconfigura a experiência, pois a própria foto se torna a experiência.

No regime da foto-ostentação, os elementos clássicos de linguagem e composição fotográfica são dispensáveis - e, quando existem, servem para agregar valor de exposição às fotografias. Nesse ponto, há o distanciamento do academicismo fotográfico que predominou na foto-documento, e a aproximação com as práticas expressivas e de registro familiar, gradativamente regidas por maior liberdade das regras de composição. 
Diante do que foi discutido, é possível considerar a foto-ostentação como novo paradigma fotográfico? Sim, mas entendendo que é um regime expoente, que destaca características atreladas à imagem fotográfica. O germe da ostentação esteve presente desde os primórdios da fotografia; o ato fotográfico sempre foi solene, marcado pela distinção e pelas práticas honoríficas.

É possível perceber, no decorrer da história da fotografia, a exacerbação dessas características, impulsionada pelas transformações técnicas e sociais. É preciso reiterar que a fotografia sempre foi produto e, como tal, está sujeita às dinâmicas do mercado e da lógica econômica. Assim, a foto-ostentação se apresenta como o regime dominante deste tempo, que se destaca dos demais paradigmas já consolidados, coexistentes na complexa teia das sociedades ocidentais, capitalistas e herdeiras da modernidade.

Como todo regime expoente, a foto-ostentação traz em seu cerne características dos paradigmas anteriores. Portanto, é necessário compreender o contexto sócio-histórico em que se desenvolveu para não incorrer no equívoco de tratar como novidade questões atreladas à fotografia desde sua invenção. Também deve-se atentar para o caminho oposto, ou seja, não vislumbrar características que diferem as representações fotográficas contemporâneas dos paradigmas já conhecidos, ignorando-se, assim, as novas nuances e finalidades.

\section{Referências}

BAITELLO JUNIOR, N. A era da iconofagia. São Paulo: Hacker, 2005.

BAUDRILLARD, J. Simulacros e simulações. Lisboa: Relógio d’Água, 1991.

BENJAMIN, W. A obra de arte na era de sua reprodutibilidade técnica. In: Magia e técnica, arte e política: ensaios sobre literatura e história da cultura. 8. ed. São Paulo: Brasiliense, 2012. p. 179-212. 
BOURDIEU, P. Un arte medio: ensayo sobre los usos sociales de la fotografía. Barcelona: Gustavo Gili, 2003.

DEBORD, G. A sociedade do espetáculo. Rio de Janeiro: Contraponto, 2002.

FABRIS, A. Identidades virtuais: uma leitura do retrato fotográfico. Belo Horizonte: Editora UFMG, 2004.

FONTCUBERTA, J. A câmera de Pandora: a fotografia depois da fotografia. São Paulo: Gustavo Gili, 2012.

GUINN, J.; PERRY, D. The sixteenth minute: life in the aftermath of fame. New York: Tarcher, 2005.

KEEN, A. Vertigem digital: porque as redes sociais estão nos dividindo, diminuindo e desorientando. Rio de Janeiro: Zahar, 2012.

KOSSOY, B. Realidades e ficções na trama fotográfica. 4. ed. São Paulo: Ateliê Editorial, 2009.

. Fotografia \& história. 4. ed. São Paulo: Ateliê Editorial, 2012.

LIPOVETSKY, G. O império do efêmero: a moda e seu destino nas sociedades modernas. São Paulo: Companhia das Letras, 1989.

LIPOVETSKY, G.; SERROY, J. A cultura-mundo: resposta a uma sociedade desorientada. São Paulo: Companhia das Letras, 2011.

MACHADO, J. A sociedade medíocre: passagem ao hiperespetacular - o fim do direito autoral, do livro e da escrita. Porto Alegre: Sulina, 2013. 
MEDEIROS, M. Fotografia e narcisismo: o auto-retrato contemporâneo. Lisboa: Assírio e Alvim, 2000.

OLIVEIRA, M.; BONI, P. C. Dos álbuns às redes virtuais: a midiatização da fotografia de família. Tríade, Sorocaba, v. 3, n. 5, 2015.

ROUILLÉ, A. Fotografia: entre documento e arte contemporânea. São Paulo: Editora Senac, 2009.

SCHWARCZ, L. M. As barbas do imperador: D. Pedro II, um monarca nos trópicos. São Paulo: Companhia das Letras, 1998.

SIBILIA, P. O show do eu: a intimidade como espetáculo. Rio de Janeiro: Nova Fronteira, 2008.

SONTAG, S. Sobre fotografia. São Paulo: Companhia das Letras, 2004.

VEBLEN, T. A teoria da classe ociosa: um estudo econômico das instituições. São Paulo: Abril Cultural, 1983.

submetido em: 15 ago. 2017 | aprovado em: 02 out. 2017 